\title{
Multi-technique characterization of madder lakes: a comparison between non- and micro- destructive methods
}

\author{
B. Campanella ${ }^{1}$, E. Grifoni ${ }^{1}$, M. Hidalgo ${ }^{2}$, S. Legnaioli ${ }^{1 *}$, G. Lorenzetti ${ }^{1}$, S. Pagnotta ${ }^{1}$, \\ F. Poggialini ${ }^{1}$, L. Ripoll-Seguer ${ }^{2}$, V. Palleschi ${ }^{1}$ \\ ${ }^{1}$ Applied and Laser Spectroscopy Laboratory, Institute of Chemistry of Organometallic Compounds, \\ Research Area of CNR, Via Giuseppe Moruzzi, 1, 56124 Pisa (Italy) \\ ${ }^{2}$ Department of Analytical Chemistry and Food Science and University Institute of Materials, University of \\ Alicante, Apdo. 99, E-03080 Alicante (Spain). \\ *s.legnaioli@pi.iccom.cnr.it
}

\begin{abstract}
The chemical characterization of paint material is paramount for the understanding of painting techniques, provenance studies and for assessing conservation strategies. In particular, the chemical characterization of both the organic and inorganic fraction of lakes is fundamental to assess the technologies used in their production. In this short note, we present a pilot study by comparing several micro-destructive and non-destructive methods for the comprehensive characterization of the organic and inorganic fraction of reference madder lakes. In the final procedure, the chromophores-containing molecules were separated using a sample preparation procedure based on acid hydrolysis and solvent extraction, and analysed by high-pressure liquid chromatography with UV-Vis detector (HPLC-UV/Vis). Laser induced breakdown spectroscopy (LIBS) and X-Ray Fluorescence (XRF) were used for the study of the elemental composition. Multispectral Imaging was also applied in order to evaluate its potentialities to distinguish amongst different red lakes. The final multi-technique method allowed for the characterization of both organic and inorganic fraction from the same lake micro sample.
\end{abstract}

\section{Keywords}

Madder lakes; Multispectral Imaging, X-Ray Fluorescence, LIBS, HPLC-UV/Vis 


\section{Introduction}

A lake is an artificial pigment constituted by one or more organic natural dyes fixed by absorption or complexation on an insoluble inorganic material [1]. Organic dyes are indeed soluble in water or in other binding media and they need to be transformed into lakes, which are insoluble in binders and thus suitable to be used for painting purposes. Potash alum $\left(\mathrm{KAl}\left(\mathrm{SO}_{4}\right)_{2} \cdot 12 \mathrm{H}_{2} \mathrm{O}\right)$, ammonium alum $\left(\mathrm{Al}_{2}\left(\mathrm{NH}_{4}\right)_{2}\left(\mathrm{SO}_{4}\right)_{4} \cdot 12 \mathrm{H}_{2} \mathrm{O}\right)$, iron sulphate $\left(\mathrm{FeSO}_{4}\right)$, and tin(II) chloride $\left(\mathrm{SnCl}_{2}\right)$ are among the salts commonly used as mordants in lake pigments making [2].

Before the introduction of synthetic dyes, the most important lakes were those obtained from anthraquinoid dyestuffs, such as madder lake, kermes lake, cochineal lake and Indian lac [3]. The characterization of lakes is of utmost importance to inform conservation practice, being lakes amongst the most fugitive materials in paintings. The source of the dye, substrate, metal cation and dye/cation ratio are all crucial parameters affecting the light-fastness and chemical features of the lakes $[1,4]$. Usually only tiny amounts of examined paints can be sampled in contrast to other objects, for instance textiles, for which sampling procedures are usually more flexible.

Several methods have been developed to analyze anthraquinoid dyes in lakes painting matrices in the last twenty years, exploiting different analytical techniques and testing different sample pretreatment procedures. Most of them are based on High Pressure Liquid Chromatography coupled with Diode-Array, Fluorescence or Mass Spectrometric Detectors (HPLC-DAD-FD-MS) [5,6], but also 3D Fluorescence and Surface Enhanced Raman Spectroscopy (SERS) are employed [7,8]. On the other hand, literature references on the characterization of inorganic mordants are scarce. Most of the studies are focused on the determination of the coordination, structures and photo-physical properties of anthraquinoid lakes [9]. Only few studies report the characterization of the mordant in textiles artworks by XRF or inductively coupled plasma-mass spectrometry [10,11], or used multianalytical approaches for the study of both organic and inorganic composition in paints [12$16]$.

In this paper, a multi-analytical approach has been developed to characterize three reference madder lakes containing different metal cations. Multispectral Imaging provided us a first discrimination. Then, a previously developed extraction procedure based on acid hydrolysis was applied to separate the inorganic fraction from the organic one. The organic phase containing the pigments was analysed by HPLC-UV/Vis. The inorganic mordant was characterized both by LIBS and XRF.

\section{Materials and Methods}

\subsection{Materials}

Water (Carlo Erba, Italy), hydrochloric acid ( $\mathrm{HCl}, 37 \%$, Merck, Germany), methanol (MeOH; LC/MS grade Sigma-Aldrich USA), formic acid (LC/MS grade Sigma-Aldrich USA) and n-heptane (Carlo Erba, Italy) were used for sample pre-treatment and HPLC-DAD analyses. Whatman RC Mini-Uniprep ( $0.20 \mu \mathrm{m}$ pore diameter, Sigma Aldrich) were chosen for filtration. Ultrapure water prepared with an Elga Purelab-UV system (Veolia Environment, France) was used throughout.

Reference madder lake powders N.37203 (Natural Red 9, madder red pigment precipitated with tin salt), 372051 (Natural Red 8) and 372057 (Natural Red 9, madder red pigment precipitated with copper salt) were supplied by Kremer Pigmente GmbH \& Co (Germany). Linseed oil (Maimeri Company, Italy), rabbit glue (C.T.S., Italy) and gypsum ( $\mathrm{CaSO}_{4} \cdot 2 \mathrm{H}_{2} \mathrm{O}$, C.T.S., Italy) were used as binder and fillers for the preparation of paint model systems. A barium sulfate $\left(\mathrm{BaSO}_{4}\right)$ disk was 
used as reference white in all reflectance and imaging measurements.

\subsection{Paint model systems}

Three paint model systems were prepared on wooden panels and were composed of three layers: the preparation layer, the priming layer and the painting layer. The preparation layer, consisting in a solution of rabbit glue in water (1:16) saturated with gypsum, was applied on the panel in a six-fold coating. The priming layer, constituted by a solution of rabbit glue in water (1:32), was applied on top of the preparation layer. The ratios between glue and water are based on protocols found in the literature [17]. Three painting layers, consisting in a mixture of red lake and linseed oil, were applied on top of the priming layer. The ratio between the oil and the lake was evaluated time to time to achieve tonal uniformity.

\subsection{Multispectral analysis}

The multiband and fluorescence images were acquired using an 8.3 Megapixels Chroma C4 scientific camera (DTA Scientific Instruments s.r.l., Italy). Multi-band images were acquired using six interferential filters (centred at 400, 450, 550, 600, 750 and $1.050 \mathrm{~nm}$, with band-pass $\pm 25 \mathrm{~nm}$ ) in front of the CCD sensor. All the images were white-balanced using a reference barium sulfate white and then combined to form single high-resolution images of the whole sample. The classical four bands (RGB + IR) were used to build RGB, false colours and UV-Visible fluorescence images. The UV-Visible fluorescence image was obtained illuminating the painting with UV LEDs emitting at $395 \mathrm{~nm}$.

\subsection{Sample preparation and HPLC analysis}

A micro-sample $(<0.1 \mathrm{mg})$ taken from the surface of the lake preparation were suspended in 200 $\mu \mathrm{L}$ of $0.1 \%$ EDTA/DMF solution (1:1), and sonicated for $1 \mathrm{~h}$ at $60{ }^{\circ} \mathrm{C}$. The extract in EDTA/DMF was filtrated through a RC Mini-Uniprep filter and then injected in the HPLC-DAD system. Chromatographic separation was achieved using an analytical reverse-phase Poroshell 120 SB-C18 (2.1 mm x $50 \mathrm{~mm}, 2.7 \mu \mathrm{m}$, Agilent Technologies).

The HPLC system consists of an Infinity 1260 HPLC (Agilent Technologies), equipped with a gradient pump, a vacuum membrane degasser, an injection valve, and a variable wavelength detector. The working conditions were: column temperature $40{ }^{\circ} \mathrm{C}$, injection volume $2 \mu \mathrm{L}$, flow rate $0.8 \mathrm{~mL} / \mathrm{min}$. The two eluents were $0.1 \%$ phosphoric acid (A) and acetonitrile (B). The elution program was $15 \%$ B for $1.2 \mathrm{~min}$, up to $50 \%$ B in $5.8 \mathrm{~min}$, up to $70 \%$ B in $2.2 \mathrm{~min}$, up to $90 \%$ B in $0.3 \mathrm{~min}$, hold for $1 \mathrm{~min}$. UV spectra were acquired at $250-435$ - $460 \mathrm{~nm}$ every $0.025 \mathrm{~min}$ with a resolution of $2 \mathrm{~nm}$.

\subsection{XRF analysis}

All experiments were performed using the Elio portable XRF Analyzer (XGLab, Italy), equipped with a $50 \mathrm{keV} / 200 \mu \mathrm{A}$ X-ray tube (Rh electrode, $1 \mathrm{~mm}$ collimated beam on the sample) and a largearea Energy Dispersive Si-Drift detector (130 eV FWHM at $\mathrm{Mn} \mathrm{K}_{\alpha}$ ).

\subsection{LIBS analysis}

All experiments were performed with a Modì double pulse LIBS instrument (Marwan Technology, Italy). LIBS spectra were acquired in collinear double-pulse mode (70 mJ per pulse at $1064 \mathrm{~nm}$ in 15 ns FWHM pulses); the focusing lens had a focal length of $10 \mathrm{~cm}$; the signal was collected with 
an optical fiber, placed at an angle of 45 degrees with respect to the beam direction. The tip of the optical fiber was placed about $2 \mathrm{~cm}$ from the surface to collect the signal from the whole laserinduced plasma. The signal was acquired with a two-channels spectrometer (AvaSpec-2048-2, Avantes, Netherland) covering the spectral range from 180 to $900 \mathrm{~nm}$; the spectral resolution of the spectrometer is $0.1 \mathrm{~nm}$ between 180 and $450 \mathrm{~nm}$ and $0.3 \mathrm{~nm}$ from 450 to $900 \mathrm{~nm}$. LIBS spectra were acquired applying a delay of $1 \mu$ s between the two pulses, $300 \mathrm{~ns}$ after the second laser pulse. The integration time was $2.5 \mathrm{~ms}$.[18].

\section{Results and Discussion}

\subsection{Multispectral analysis}

Spectral characterization of the lakes was performed by combining triplets of single-band images, as reported in Table 1S. The obtained images for the three lakes are reported in Figure 1. The comparison shows that the false color images, both in visible light and in fluorescence, only marginally improve the differences between lakes. The RGB images highlight differences in the lake casting on the wooden panel, but not on the color of the lakes themselves. As can be noted from Figure 1, the near infrared images do not show noticeable differences between the three samples. On the other hand, fluorescence and false color images allow us to distinguish sample 37203 from the others.

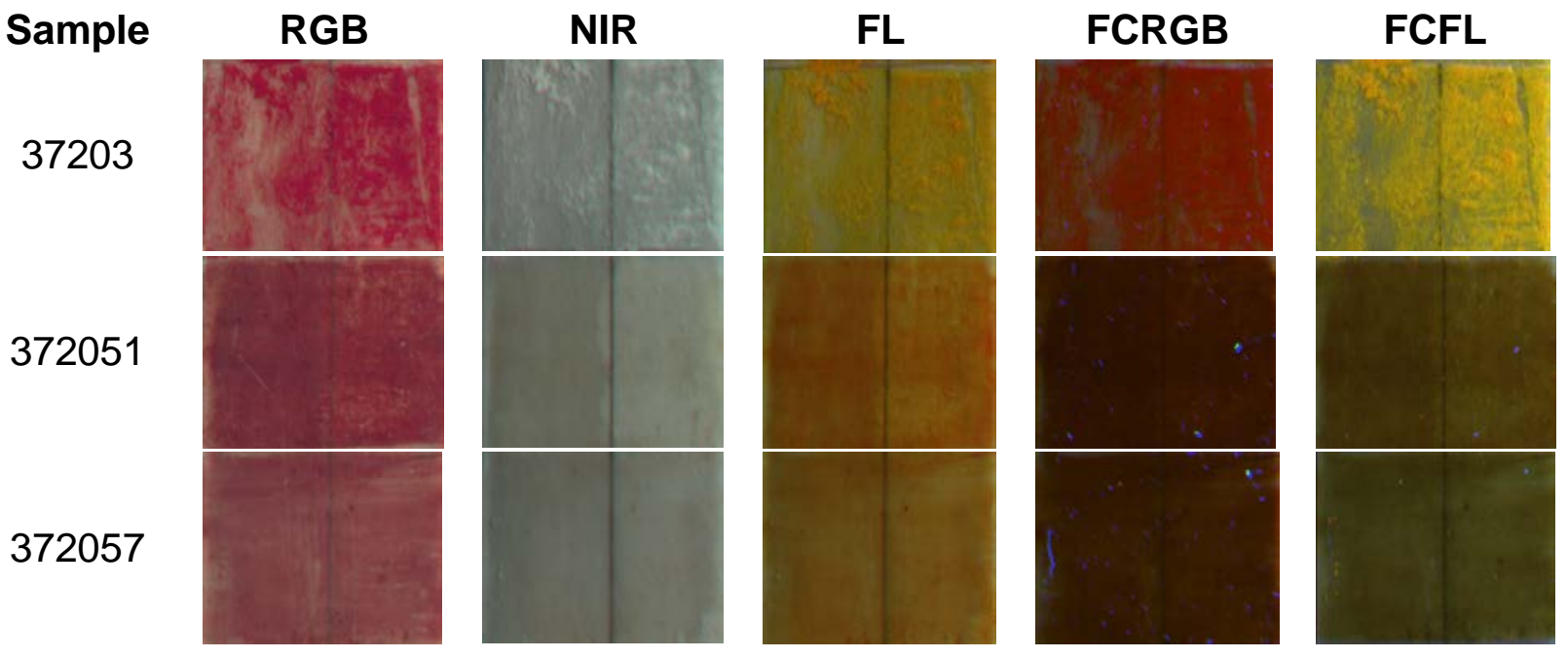

Fig. 1. From left to right: RGB, NIR, FL, false color-RGB and false color-FL images of the three lakes analysed.

The reflectance values of the three lakes were calculated for all the spectral bands by averaging raw reflectance data of the images. Values were also normalized by using barium sulphate disk as white reference. The obtained reflectance spectra are reported in Figure 1S (left). The clearest marker for identifying each spectrum is the spectral behavior in the 500-700 $\mathrm{nm}$ region, where the spectral slope makes it possible to distinguish between the three different pigments. The 37203 lake shows a slightly different behavior from the other two lakes, as already observed in Figure 1, at $600 \mathrm{~nm}$.

\subsection{XRF analysis}


XRF spectra (Figure 2) were acquired for the paint model systems as-is. High sulfur and calcium signals, deriving from the gypsum in the preparation layer, were observed in all three spectra. Chlorine and iron were also observed in all spectra and their presence is due to the lake process [2,19]. A small signal around $3.4 \mathrm{KeV}$, ascribable to the $\mathrm{L}_{\alpha}$ transition of tin, was detected in the spectrum of sample 37203. Lake 372051 spectrum showed a small peak at $5.4 \mathrm{KeV}$ corresponding to the $\mathrm{K}_{\alpha}$ transition of chromium. Finally, the 372057 spectrum showed a peak at $8.0 \mathrm{KeV}$ belonging to the $\mathrm{K}_{\alpha}$ transition of copper, and another at $3.3 \mathrm{KeV}$ which can be attributed to the $\mathrm{K}_{\alpha}$ transition of potassium.

According to the certificate of analysis of the pigments studied in this work, it is known that the mordants are tin (37203), aluminum (372051), and copper (372057). This is in agreement with the tin and copper signals found in the spectra of samples 37203 and 372057, respectively. It was not possible to ascertain the presence of aluminium in sample 372051, since energy dispersive XRF is not suitable for the analysis of light elements. Aluminum is actually visible in XRF spectra of the samples, with the exception of preparation layer (as expected). The intensity of Al signal is indeed comparable for all lakes, due to the intrinsic low resolution for $\mathrm{Al}$ of our portable instrument, so its presence is not discriminant for lakes identification. By comparing the XRF spectra of madder lakes with the spectrum of the preparation layer, it is also possible to observe iron, present in the preparation based on gypsum and animal glue.

XRF can therefore distinguish between 37203 and 372057 lakes based on their inorganic composition.

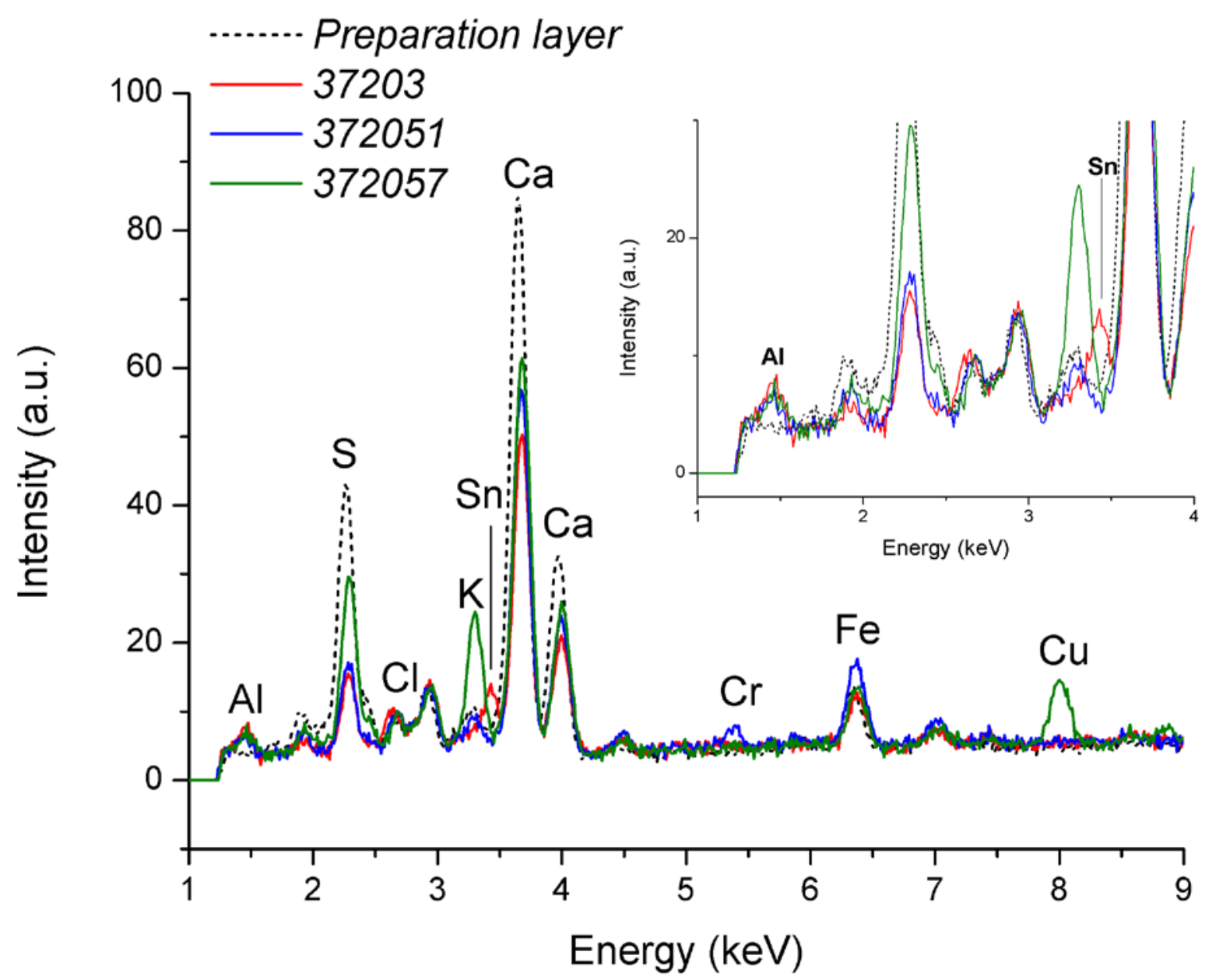

Fig. 2. XRF spectra showing elemental composition of the preparation layer (dashed black), madder 


\subsection{HPLC analysis}

HPLC analyses of lakes extracts after acid hydrolysis were carried out in order to characterize the chromophores-containing molecules.

For the extraction of dyes from their metal complexes in madder lakes, a mild extraction approach using EDTA/DMF was used as an alternative to usual treatment by strong acid solutions. It is important to notice that the application of a relatively strong extraction procedure such as the one used in this case influences the yields of the target analytes [20] and impede the discrimination of the botanical origin of the madder root employed in the lake production. Nonetheless, the composition of the lake in terms of anthraquinones is not only dependant on the botanical species, but also on the growth environment of the plant, its processing and the lake preparation [21].

The HPLC chromatograms acquired at $250 \mathrm{~nm}$ are shown in Figure 3. The three lakes presented similar compositions in terms of organic dyes, and the three marker compounds (i.e. alizarin, purpurin and rubiadin, which belong to the anthraquinones family [22]) were successfully identified through the comparison of chromatograms at 435 and $460 \mathrm{~nm}$. The peak of alizarin is present in all HPLC-UV/Vis chromatograms (tr $7.00 \mathrm{~min}$ ), while purpurin is more intense in lakes 37203 (tr 7.97 min) and rubiadin was present in samples 372057 and 372051 (tr 9.57).

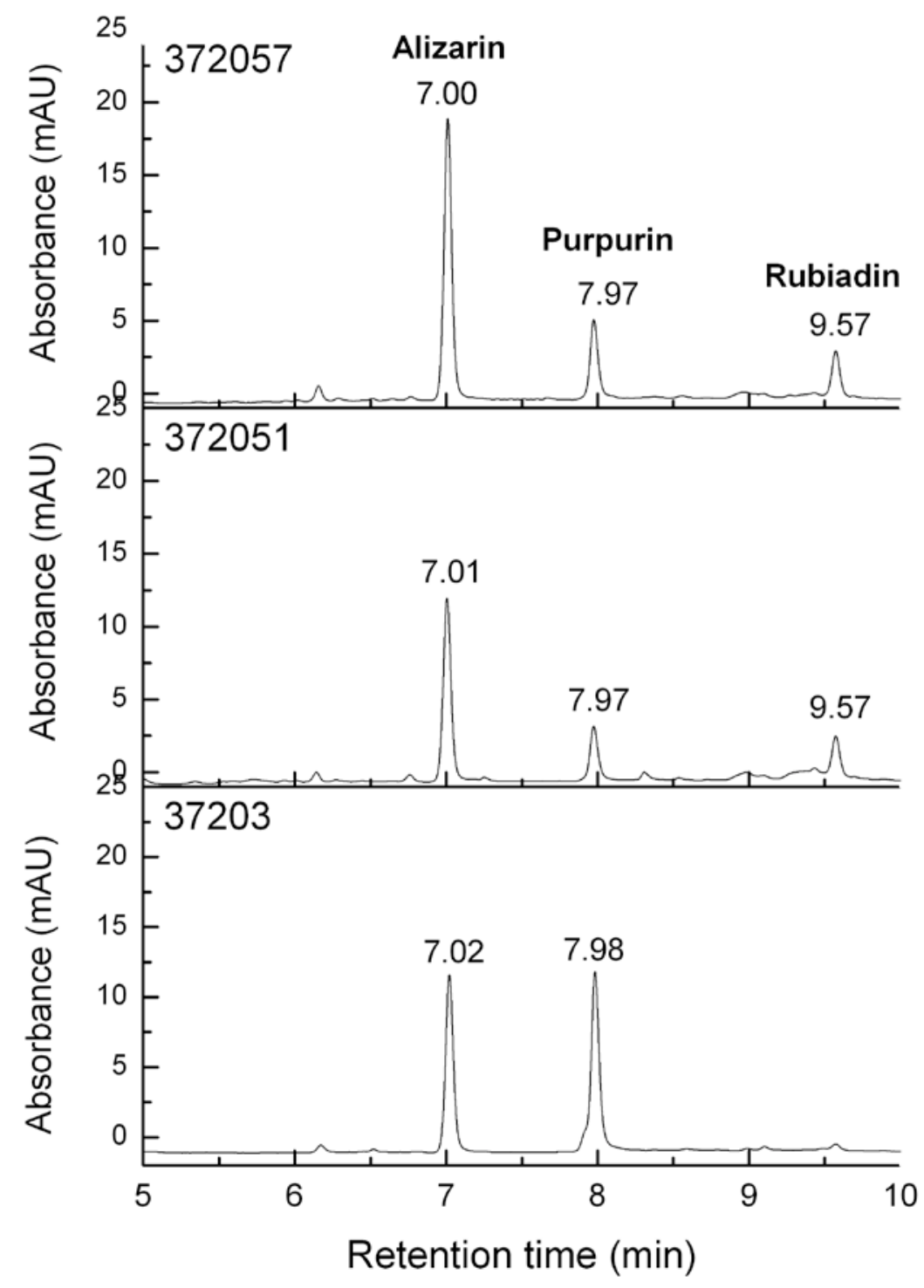


Fig. 3. HPLC-UV/Vis acquired at $250 \mathrm{~nm}$ of paint model systems prepared with lakes 372057 (top), 372051 (center), and 37203 (bottom).

\subsection{LIBS analysis}

LIBS analyses were first carried out on the paint model systems as-is. LIBS spectra from the direct analysis of paint model systems are shown in Figure 4. Aluminium and copper are clearly identified in lakes 372051 and 372057, respectively, while the signal of tin in sample 37203 is poorly resolved from the background noise.

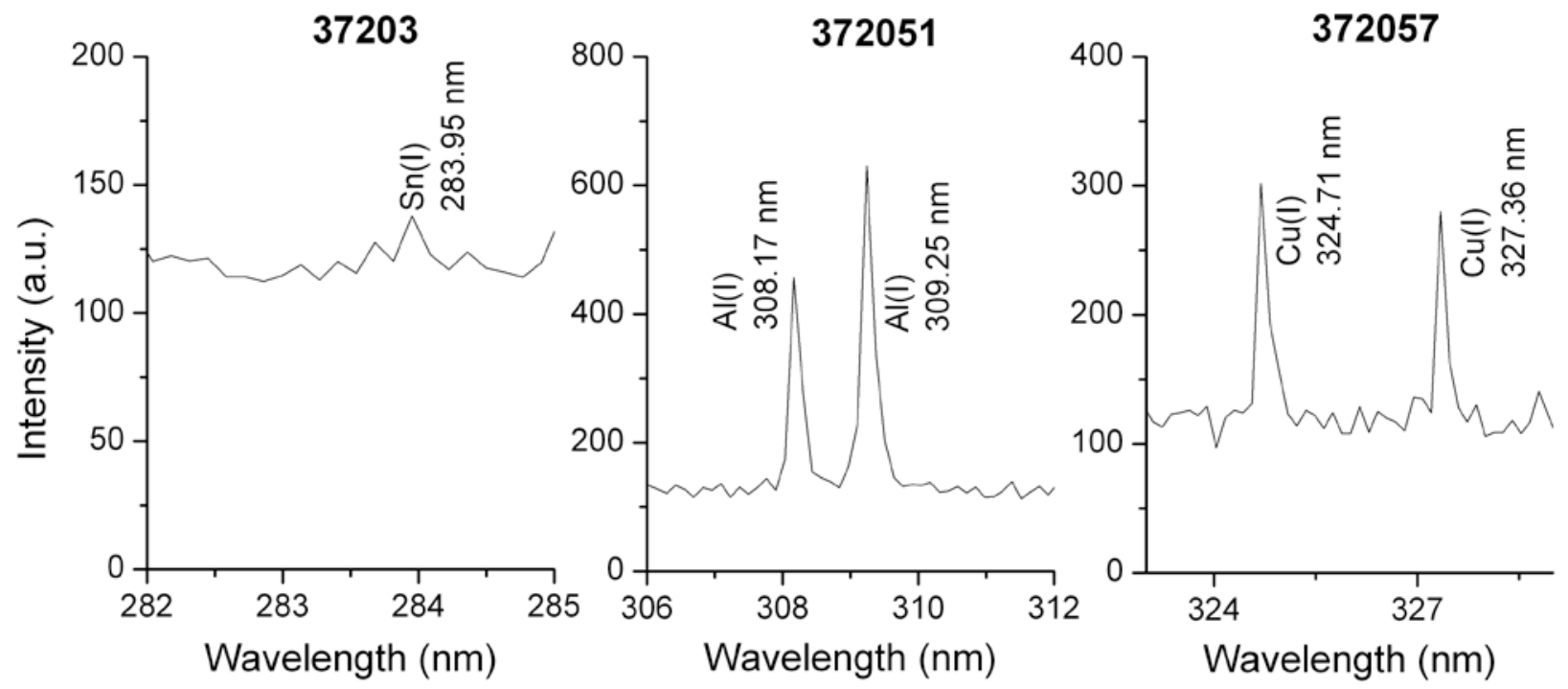

Fig. 4. LIBS spectra for madder lakes 37203 (left), 372051 (centre), and 372057 (right) on wooden support.

LIBS analysis in combination with LC-DAD/FD and XRF methods enabled the determination of composition of commercially available madder lakes. The lakes were not studied in their pure form, since a model paint was prepared on wooden panel treated with rabbit glue and gypsum (preparation layer), rabbit glue in water (priming layer), and a mixture of red lake and linseed oil (painting layer).

\section{Conclusions}

The multi-analytical approach developed in this work allowed us to highlight the potentialities and the limits of the different tested techniques in differentiating three formulations of madder lakes.

Multispectral imaging analyses showed some differences amongst the lakes. Nevertheless, it was not possible to directly and unequivocally connect them to the difference in the kind of cation, because the presence of other materials in the matrix and the lack of homogeneity of the sample surfaces cannot be neglected.

XRF analyses provided information on the mordant for two of the three lakes, but not for the one with aluminium, as predictable by the limits of the technique.

For what concerns the determination of the organic dyes, the HPLC-DAD-FD analyses, as expected, identified alizarin, purpurin and rubiadin as chromophores-containing molecules in organic extracts of the three madder lakes. Finally, LIBS analyses performed on paint model systems as-is. 
Even if the crater created on the sample surface by the laser pulse is very small, LIBS is a microdestructive technique. Thus, choosing the proposed analytical approach allowed us to decrease the destructivity towards the samples.

Further studies could enlarge the applicability of this micro-destructive approach to other kind of lakes inside painting matrices.

\section{References}

[1] I. Degano, E. Ribechini, F. Modugno, M.P. Colombini, Analytical methods for the characterization of organic dyes in artworks and in historical textiles, Appl. Spectrosc. Rev. 44 (2009) 363-410.

[2] J. Kirby, M. Spring, C. Higgitt, The technology of eighteenth-and nineteenth-century red lake pigments, Natl. Gall. Tech. Bull. 28 (2007) 69.

[3] L. Campanella, A. Casoli, M.P. Colombini, R.M. Bettolo, M. Matteini, L.M. Migneco, A. Montenero, L. Nodari, C. Piccioli, M.P. Zappala, Chimica per l’arte, Zanichelli, Bologna, Cerca Con Google. (2007).

[4] B.H. Berrie, Artists' pigments: a handbook of their history and characteristics. Vol. 4, National Gallery of Art, 2007.

[5] B.H. Berrie, Rethinking the History of Artists' Pigments Through Chemical Analysis, Annu. Rev. Anal. Chem. 5 (2012) 441-459. doi:10.1146/annurev-anchem-062011-143039.

[6] I. Degano, J. La Nasa, Trends in high performance liquid chromatography for Cultural Heritage, Top. Curr. Chem. 374 (2016). doi:10.1007/s41061-016-0020-8.

[7] Li, G., Liao, Y., Wang, X., Sheng, S., \& Yin, D., In situ estimation of the entire color and spectra of age pigment-like materials: application of a front-surface 3D-fluorescence technique. Experimental gerontology, 41 (2006), 328-336.

[8] (a) Casadio, F., Leona, M., Lombardi, J. R., \& Van Duyne, R., Identification of organic colorants in fibers, paints, and glazes by surface enhanced Raman spectroscopy, Accounts of Chemical Research. 43 (2010), 782-791; (b) Mayhew, H. E., Fabian, D. M., Svoboda, S. A., \& Wustholz, K. L., Surface-enhanced Raman spectroscopy studies of yellow organic dyestuffs and lake pigments in oil paint, Analyst. 138 (2013), 4493-4499; (c) Pozzi, F., Berg, K. J., Fiedler, I., \& Casadio, F., A systematic analysis of red lake pigments in French Impressionist and Post - Impressionist paintings by surface - enhanced Raman spectroscopy (SERS), Journal of Raman Spectroscopy. 45 (2014) 1119-1126.

[9] C. Grazia, C. Clementi, C. Miliani, A. Romani, Photophysical properties of alizarin and purpurin Al (III) complexes in solution and in solid state, Photochem. Photobiol. Sci. 10 (2011) 1249-1254.

[10] R.J. Koestler, R. Sheryll, N. Indictor, Identification of dyeing mordants and related substances on textile fibers: a preliminary study using energy dispersive X-ray spectrometry, Stud. Conserv. 30 (1985) 58-62.

[11] A. Manhita, T. Ferreira, A. Candeias, C.B. Dias, Extracting natural dyes from wool—an evaluation of extraction methods, Anal. Bioanal. Chem. 400 (2011) 1501.

[12] O. Otłowska, M. Ślebioda, M. Wachowiak, M. Śliwka-Kaszyńska, A multi-analytical approach to the characterization of natural organic dyestuffs and inorganic substrates present in the 19 th-century artistic oil paints manufactured by a French art materials supplier Richard Ainès, Anal. Methods. 9 (2017) 94-102.

[13] M. Gil, M.L. Carvalho, S. Longelin, I. Ribeiro, S. Valadas, J. Mirao, A.E. Candeias, Blue pigment colors from wall painting churches in Danger (Portugal 15th to 18th century): 
identification, diagnosis, and color evaluation, Appl. Spectrosc. 65 (2011) 782-789.

[14] F.C. Izzo, V. Capogrosso, M. Gironda, R. Alberti, C. Mazzei, L. Nodari, A. Gambirasi, E. Zendri, A. Nevin, Multi- analytical non- invasive study of modern yellow paints from postwar Italian paintings from the International Gallery of Modern Art Cà Pesaro, Venice, X- Ray Spectrom. 44 (2015) 296-304.

[15] K.F. Gebremariam, L. Kvittingen, F. Banica, Physico- Chemical Characterization of Pigments and Binders of Murals in a Church in Ethiopia, Archaeometry. 58 (2016) 271-283.

[16] G. Gautier, A. Bezur, K. Muir, F. Casadio, I. Fiedler, Chemical fingerprinting of readymixed house paints of relevance to artistic production in the first half of the twentieth century. Part I: inorganic and organic pigments, Appl. Spectrosc. 63 (2009) 597-603.

[17] Cavaleri, T., Buscaglia, P., Migliorini, S., Nervo, M., Piccablotto, G., Piccirillo, A., Pisani, M., Puglisi, D., Vaudan, D., Zucco, M., Pictorial materials database: 1200 combinations of pigments, dyes, binders and varnishes designed as a tool for heritage science and conservation, Applied Physics A. 123 (2017), 419.

[18] A. Bertolini, G. Carelli, F. Francesconi, M. Francesconi, L. Marchesini, P. Marsili, F. Sorrentino, G. Cristoforetti, S. Legnaioli, V. Palleschi, Modì: a new mobile instrument for in situ double-pulse LIBS analysis, Anal. Bioanal. Chem. 385 (2006) 240-247.

[19] W. Herbst, K. Hunger, Industrial organic pigments: production, properties, applications, John Wiley \& Sons, 2006.

[20] J. Wouters, High performance liquid chromatography of anthraquinones: analysis of plant and insect extracts and dyed textiles, Stud. Conserv. 30 (1985) 119-128.

[21] C. Mouri, R. Laursen, Identification of anthraquinone markers for distinguishing Rubia species in madder-dyed textiles by HPLC, Microchim. Acta. 179 (2012) 105-113.

[22] L. Valianou, I. Karapanagiotis, Y. Chryssoulakis, Comparison of extraction methods for the analysis of natural dyes in historical textiles by high-performance liquid chromatography, Anal. Bioanal. Chem. 395 (2009) 2175-2189. 